ORIGINAL ARTICLE

\title{
Bed-sharing and the infant's thermal environment in the home setting
}

\author{
S A Baddock, B C Galland, M G S Beckers, B J Taylor, D P G Bolton
}

Arch Dis Child 2004;89:1111-1116. doi: 10.1136/adc.2003.048082

See end of article for authors' affiliations

.....................

Correspondence to:

Dr B Galland, Department

of Women's \& Children's

Health, University of

Otago, PO Box 913 ,

Dunedin, New Zealand;

barbara.galland@

stonebow.otago.ac.nz

Accepted 15 July 2004

\begin{abstract}
Aims: To study bed-sharing and cot-sleeping infants in the natural setting of their own home in order to identify differences in the thermal characteristics of the two sleep situations and their potential hazards. Methods: Forty routine bed-sharing infants and 40 routine cot-sleeping infants aged 5-27 weeks were individually matched between groups for age and season. Overnight video and physiological data of bedshare infants and cot-sleeping infants were recorded in the infants' own homes including rectal, shin, and ambient temperature.

Results: The mean rectal temperature two hours after sleep onset for bed-share infants was $36.79^{\circ} \mathrm{C}$ and for cot-sleeping infants, $36.75^{\circ} \mathrm{C}$ (difference $0.05^{\circ} \mathrm{C}, 95 \% \mathrm{Cl}-0.03$ to 0.14 ). The rate of change thereafter was higher in the bed-share group than in the cot group $\left(0.04^{\circ} \mathrm{C} v 0.03^{\circ} \mathrm{C} / \mathrm{h}\right.$, difference $0.01,0.00$ to 0.02). Bed-share infants had a higher shin temperature at two hours $\left(35.43 \vee 34.60^{\circ} \mathrm{C}\right.$, difference 0.83 , 0.18 to 1.49$)$ and a higher rate of change $\left(0.04 v-0.10^{\circ} \mathrm{C} / \mathrm{h}\right.$, difference $0.13,0.08$ to 0.19$)$. Bedsharing infants had more bedding. Face covering events were more common and bed-share infants woke and fed more frequently than cot infants (mean wake times/night: 4.6 v 2.5 ).

Conclusions: Bed-share infants experience warmer thermal conditions than those of cot-sleeping infants, but are able to maintain adequate thermoregulation to maintain a normal core temperature.
\end{abstract}

B ed-sharing, the norm in many cultures, is becoming more common in Caucasian societies. ${ }^{1-3}$ Benefits include ease of breast feeding, reduced tiredness, having a more settled baby, ${ }^{4-7}$ increased breast feeding, and increased mother-baby interactions and arousals. ${ }^{8-11}$

Bed-sharing, though not a risk factor in itself, is reported to interact to increase the risk of SIDS with many factors, including: maternal smoking, ${ }^{12-17}$ alcohol or illicit drug consumption, ${ }^{13-17}$ maternal excessive weight, ${ }^{18}$ overtiredness, household overcrowding, excessive bedding, ${ }^{13}$ soft bedding, ${ }^{19}$ other bed-sharers, ${ }^{20}$ and younger infant age. ${ }^{13} 1718$

The major postulated mechanisms regarding the risk associated with the combination of maternal smoking in pregnancy and bed-sharing include rebreathing, respiratory obstruction, and hyperthermia. Following in-utero exposure to cigarette smoke an infant may be less able to respond appropriately to any of these stresses..$^{21-23}$

Hyperthermia due to excessive bedding and/or clothing and its possible contribution to SIDS has been widely studied. ${ }^{24-27}$ It has been suggested that death could result from central disruption of respiratory ${ }^{28}$ or arousal mechanisms associated with hyperthermia. ${ }^{29}$ It is unclear whether hyperthermia may pose a greater risk during bed-share sleep or not. Tuffnell and colleagues, ${ }^{30}$ in overnight home studies, found that bed-sharing infants had a significantly higher rectal temperature than infants sleeping alone. Sleep laboratory studies have not found this increase in rectal temperature (Sawczenko, personal communication), ${ }^{31}$ but an increase in peripheral, forehead, and within-bed temperatures $^{32}$ and an increase in axillary temperature. ${ }^{33}$

The main aim of this study was to monitor infants sleeping with their parent(s) in their home to capture childcare practices in their natural physical environment and to identify the behavioural and physiological risks and/or benefits of bed-sharing compared to cot-sleeping. This paper reports on the thermal environment of these infants.

\section{METHODS}

Two groups of infants were studied: 40 bed-sharing infants and 40 cot-sleeping infants. Bed-sharing infants regularly slept in the parental bed for a minimum of five hours/night. Cot-sleeping infants regularly slept in a cot or bassinette in the parental bedroom at least five hours/night. Bed-sharing infants were recruited through postnatal organisations in Dunedin and through advertisements in local media. Cotsleeping infants matched for age and season of study were recruited from the postnatal ward of the local maternity hospital. Infants were aged 0-6 months and were over 37 weeks gestation (except for two infants in each group that were 28 and 32 weeks gestation respectively). All infants were without prenatal or postnatal complications.

\section{Protocol}

The study was approved by the Southern Regional Health Authority Ethics Committee, New Zealand (protocol no. 97/ 04/036). Informed consent was obtained from the parent(s) of all infants studied. Infants were monitored over two consecutive nights in their own home in their usual sleep situation: bed-share or cot-sleep. The first night involved video recording only and the second night involved video and physiological recording. Information was collected on layers of over-bedding, under-bedding, and infant clothing used on the study night.

\section{Physiological recordings}

The infant was set up for the study during the hour before usual bedtime. This involved placement of ECG electrodes (modified lead II position), a pulse oximeter probe around the foot for measurement of heart rate and arterial oxygen saturation from the pulse oximeter (Nellcor N-200, Nellcor Hayward, CA, USA), and respibands around the chest and abdomen for measurement of respiratory pattern by inductive plethysmography (Respitrace model 150; Respitrace Co., 
NY, USA). A thermistor (EdenTec Corporation, Eden Prairie, MN, USA) was attached under the infant's nares to monitor respiratory flow. Rectal and peripheral (shin) temperature were measured using semiconductor devices with a relative accuracy of $0.01{ }^{\circ} \mathrm{C}$. Temperature measurements were sampled at $1 \mathrm{~Hz}$. Ambient temperature was recorded $30 \mathrm{~cm}$ from the ground.

Leads from sensors were secured together as a 4 metre "umbilical cord" arrangement connected to the recording apparatus. All physiological signals were relayed through the hardware/software system of a portable polygraphic system (BabyLog Link; Christchurch Hospital, NZ).

\section{Video recordings}

A small surveillance camera (Panasonic CEC-C38, Japan) and infrared light source allowed recordings on a time-lapse video recorder (Panasonic AG-TL700) of the infant's position, movements, and parent/infant interactions.

\section{Data analysis}

\section{Temperature data}

Overnight temperature profiles for bed-share and cot-sleep infants were produced from BabyLog data records by calculating the mean rectal, shin, and ambient temperatures for each 30 minute epoch, commencing when the infant fell asleep in bed until final waking in the morning, including when the infant was awake or feeding. Figure 1 shows typical examples of temperature profiles from one infant.

Off-line video data analysis incorporated C Video software (Envisionology, CA) to link the time counter from the video recorder with a key command on the computer enabling the start and end times for each behavioural event (for example, waking) to be logged into the database (File Maker Pro 2.0, Claris Corporation, USA). Sleep and awake periods were identified from the video. Sleep was defined as starting after the infant was settled for two minutes. Arousals lasting more than two minutes were described as "awake". The infant's sleep position, movements, episodes of face covering by blankets, and number of feeding sessions were observed from the video and logged on the database. Any separate feeding initiated within 30 minutes of the previous session was included in that session.

Thickness of bedding and clothing were estimated using the layers of sheet, blankets and duvets, and itemised clothing, and applying average measured thicknesses of typical New Zealand bedding and clothing of these types (Wilson, personal communication). Effective "dry" thermal insulation was calculated for bedding and clothing of each

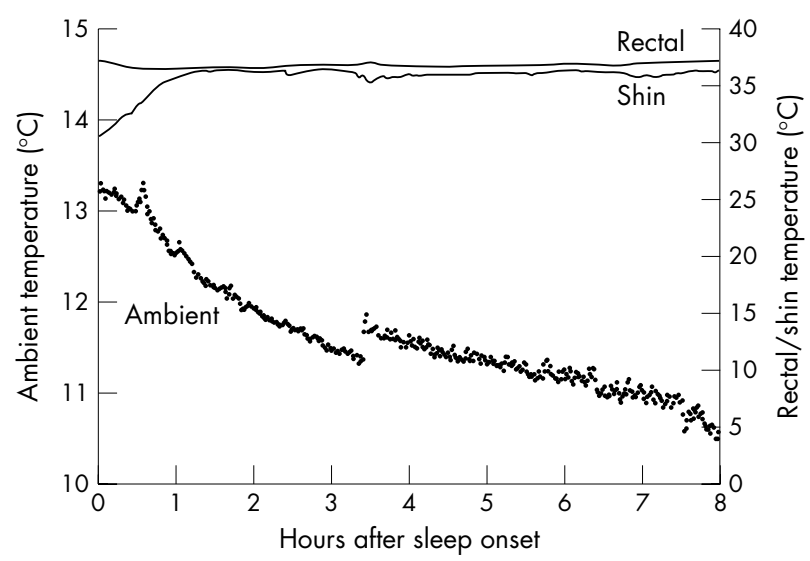

Figure 1 Profile of the rectal, shin, and ambient temperature averaged every minute during an overnight sleep study from one bed-sharing infant. infant using a predictive equation developed to estimate thermal resistance of flat multiple-layer combinations of materials. ${ }^{34}$

\section{Statistical analysis}

Although bed-share and cot-sleep infants were matched for age and season of study, data for both members of the pair were not always available. Data were therefore analysed as two groups, and a form of regression analysis, adjusted for infant age and season, was used to take the matching into account for all comparisons. Log transformations were used to calculate the geometric means (to provide a better measure of central tendency than arithmetic means) for the characteristics of the bedding. In this case the results were presented as ratios of the geometric means with 95\% confidence intervals. Poisson or logistic regression was used to estimate the relative risk or odds ratio for the bed-sharing group for the variables based on counts or categories using the cot group as the reference group. A random coefficient model with a random effect for participant was used to analyse the temperature data. As the effect of time was different for bed-share and cot-sleep infants, the results are presented as temperature at 2 hours and change per hour from 2 to 8 hours after sleep onset, together with differences between groups and 95\% CI.

\section{RESULTS}

Table 1 presents characteristics of the two groups of infants. Study groups were comparable with respect to gestational age, birth weight, sex ratio, and age and weight at study. All bed-share infants and 35/40 cot infants were breast fed. Of the 40 bed-share infants, $90 \%$ bed-shared every night, 22 slept with one adult (three with sibling included), and 18 with two adults (one with sibling included). Table 2 gives the characteristics of the mother; similar numbers were educated to tertiary level, and a small number in both groups were identifyied as Maori. Smoking was more common in the cot group $(25 \%)$ compared to the bed-sharing group $(7.5 \%)$. Maternal age was similar (bed-sharing: 28 years (SD 5.6) $v$ cot-sleeping:30 (5.5), $\mathrm{p}=0.14$ ). Maternal alcohol consumption was minimal in both groups, ranging from rarely to 3 glasses of wine or beer per week, with 17/40 bed-sharers and 15/40 mothers of cot-sleepers reporting no alcohol consumption during or after pregnancy. Mothers reported ease of breast feeding, a more settled baby, a more natural practice, closeness, and security as reasons for bed-sharing.

Some parents did not allow infant rectal temperature measurement (12/40 bed-share and 12/40 cot-sleeping), resulting in a smaller subgroup for rectal temperature analysis. Overnight rectal temperature profiles for the two groups, shown in fig 2, illustrate the mean for each 30 minute epoch. Rectal temperature fell to a nadir during the first two hours of sleep followed by a gradual rise throughout the night. Figure 3 shows that overnight shin temperatures of bed-share infants were higher than cot infants from 2 hours

Table 1 Infant group characteristics

\begin{tabular}{llll}
\hline Study group & $\begin{array}{l}\text { Bed-sharing } \\
\text { mean (SD) } \\
\text { (n=40) }\end{array}$ & $\begin{array}{l}\text { Cot-sleeping } \\
\text { mean (SD) } \\
\text { (n= 40) }\end{array}$ & p \\
\hline Birth weight (g) & $3583(735)$ & $3562(671)$ & 0.90 \\
Gestation (wk) & $39.8(2.7)$ & $* 39.5(2.7)$ & 0.69 \\
Study weight (g) & $6580(1301)$ & $* 6594(1265)$ & 0.97 \\
Sex (female)t, $\mathrm{n}(\%)$ & $17(43)$ & $18(45)$ & 0.90 \\
Breast fed $\neq, \mathrm{n}(\%)$ & $40(100)$ & $35(88)$ & 0.05 \\
\hline
\end{tabular}

*Data missing from one infant.

$\dagger \chi^{2}$ test; $\neq$ Fisher's exact test. Comparisons adjusted for season and infant age. 


\begin{tabular}{lcccl} 
Table 2 & Maternal group characteristics \\
\hline Study group & $\mathbf{n}$ & $\begin{array}{l}\text { Bed-sharing } \\
\mathbf{n}(\%)\end{array}$ & $\begin{array}{l}\text { Cot-sleeping } \\
\mathbf{n} / \mathbf{n}(\%)\end{array}$ & $\mathbf{p}$ \\
\hline $\begin{array}{l}\text { Smoking at mid } \\
\text { trimester }\end{array}$ & 38 & $3(8)$ & $10(25)$ & 0.06 \\
$\begin{array}{l}\text { Tertiary education* } \\
\text { Ethnicity }\end{array}$ & 26 & $23(88)$ & $25(96)$ & 0.31 \\
$\quad$ Maori & 40 & $4(10)$ & $7(18)$ & \\
$\quad$ European & & $31(78)$ & $23(58)$ & 0.18 \\
$\quad$ Other & $5(13)$ & $10(25)$ & \\
\hline
\end{tabular}

*Fisher's exact test; $\dagger \chi^{2}$ test. Comparisons are adjusted for season and infant age.

$\ddagger$ Tertiary refers to any post-high school education.

after sleep onset. The differences between rectal and shin temperatures are shown in fig 4 as an indication of temperature control responses. Analyses of the differences in overnight temperatures are shown in table 3 . The mean rectal temperature at 2 hours after sleep onset for bed-share infants was $36.79^{\circ} \mathrm{C}$ and for cot-sleeping infants, $36.75^{\circ} \mathrm{C}$. Thereafter, temperature increased at a significantly higher rate in bed-share infants $\left(0.04^{\circ} \mathrm{C} / \mathrm{h}\right)$ than cot-sleeping infants $\left(0.03^{\circ} \mathrm{C} / \mathrm{h}\right)$. Bed-share infants had a higher shin temperature than cot-sleeping infants at 2 hours $\left(35.43 v 34.60^{\circ} \mathrm{C}\right)$ and a higher rate of change thereafter $\left(0.04 v-0.10^{\circ} \mathrm{C} / \mathrm{h}\right)$. Bedshare infants had a significantly smaller rectal-shin temperature difference than cot infants at 2 hours. Thereafter there was no change in the rectal-shin difference in the bed-share group, but an increase in the cot-sleep group. Ambient temperature for the bed-share group was significantly cooler than for the cot group.

Table 4 shows the estimated effective thickness for bedding and clothing for the two groups of infants. Bed-sharing infants had significantly thicker bedding and hence more thermal insulation than cot-sleeping infants. The thermal insulation of the clothing was not significantly different between groups.

Table 5 summarises further characteristics of the two groups on the night of study that could affect infant temperature. Most bed-share infants slept on their side, while cot infants most commonly slept supine. Only two infants, both cot sleepers, slept prone for the majority of the night. Face covering with overbedding was significantly more common in the bed-share group, with episodes identified from 29 bed-share and five cot infants. During the night, bed-share infants woke significantly more frequently (mean

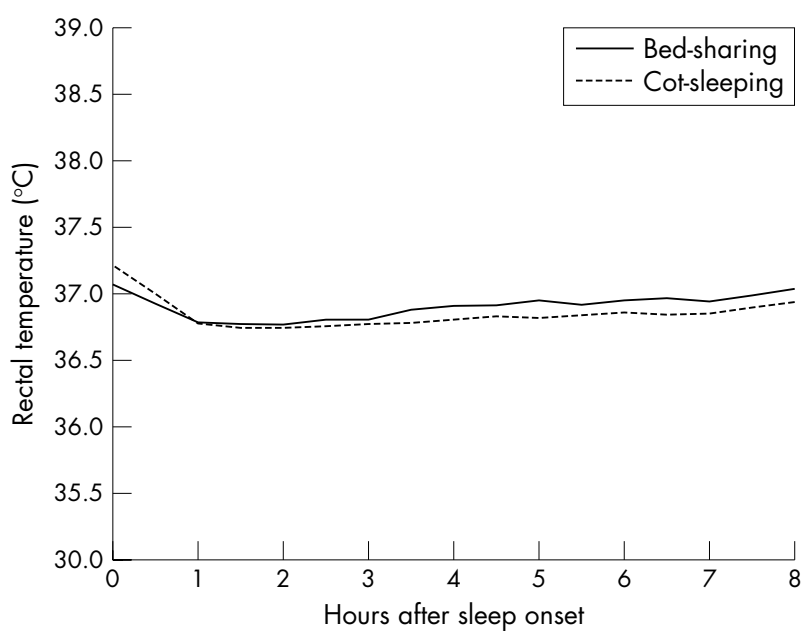

Figure 2 Overnight mean rectal temperature calculated for 30 minute epochs in the bed-share and cot-sleeping infants.

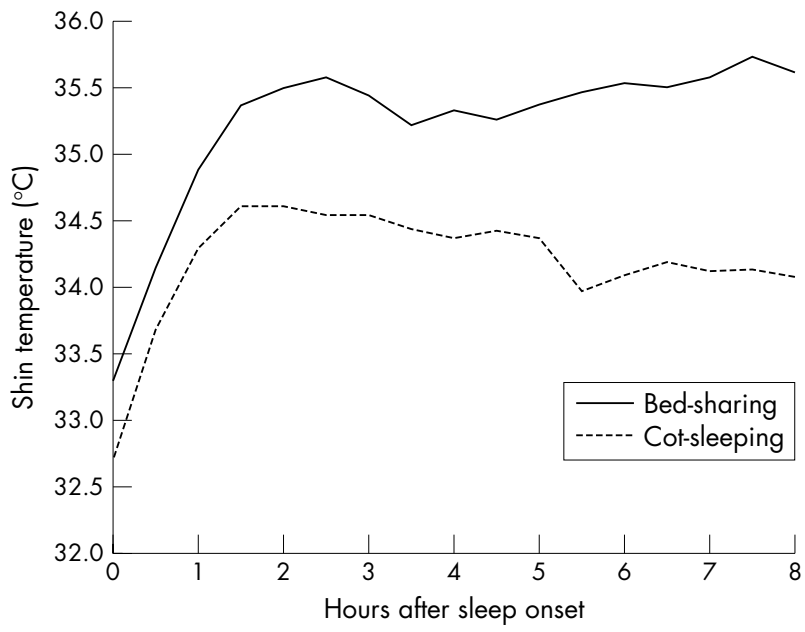

Figure 3 Overnight mean shin temperature calculated for 30 minute epochs in the bed-share and cot-sleeping infants.

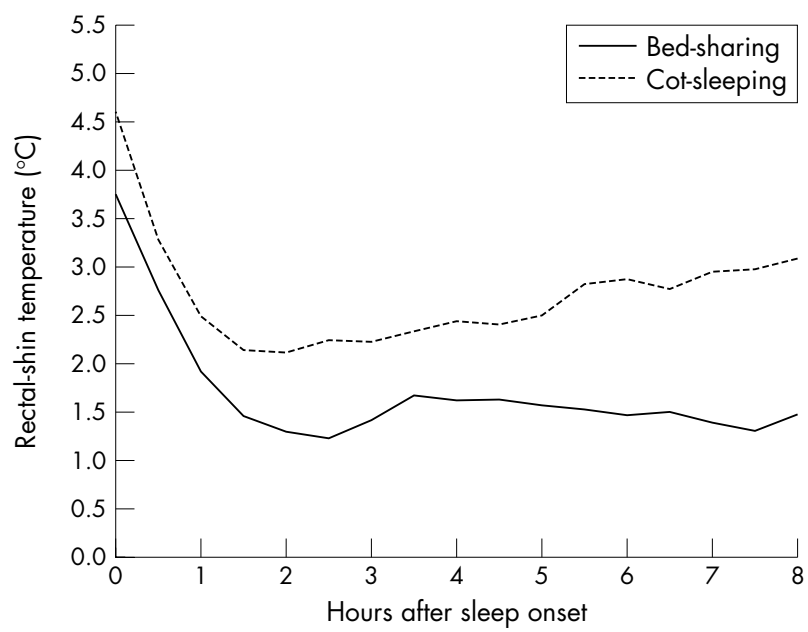

Figure 4 Overnight mean rectal-shin temperature difference calculated for 30 minute epochs in the bed-share and cot-sleeping infants.

times/night: $4.6 v 2.5$ ) and fed more frequently, although the total time awake was not significantly different between groups. The number of movements per hour was similar between groups.

\section{DISCUSSION}

This study clearly shows differences in the thermal environment between bed-share and cot-sleep infants sleeping in the parental bedroom. While the difference in rectal temperature between groups at two hours after sleep onset was not significant, the rate of increase in rectal temperature in the bed-share group was slightly higher than that of the cot-sleep group, leading to an increased temperature difference in the latter part of the night. Tuffnell and colleagues ${ }^{30}$ reported a mean overnight rectal temperature difference of $0.1{ }^{\circ} \mathrm{C}$ from a retrospective case-control home study of 34 bed-share and 34 cot-sleeping infants (not necessarily in the parents' bedroom but matched for age, ambient temperature, and estimated thermal insulation from bedding and clothing). In our study, the model predicted a similar rectal temperature difference after approximately eight hours sleep. Sawczenko (personal communication) and Ball ${ }^{31}$ did not find a significant 
Table 3 Summary of the mean temperature data two hours after sleep onset, including the mean rate of change thereafter (to eight hours after sleep onset)

\begin{tabular}{|c|c|c|c|}
\hline Study group & Bed-sharing $(n=28)$ & Cot-sleeping $(n=28)$ & Difference $(95 \% \mathrm{Cl})$ \\
\hline \multicolumn{4}{|l|}{ Rectal ( $\left.{ }^{\circ} \mathrm{C}\right)$} \\
\hline Mean at $2 \mathrm{~h}$ & 36.79 & 36.75 & $0.05(-0.03$ to 0.14$)$ \\
\hline Rate of change/h & 0.04 & 0.03 & 0.01 (0.00 to 0.02$)$ \\
\hline \multicolumn{4}{|l|}{ *Shin ( $\left.{ }^{\circ} \mathrm{C}\right)$} \\
\hline Mean at $2 \mathrm{~h}$ & 35.43 & 34.60 & $0.83(0.18$ to 1.49$)$ \\
\hline Rate of change/h & 0.04 & -0.10 & $0.13(0.08$ to 0.19$)$ \\
\hline \multicolumn{4}{|l|}{${ }^{*} \Delta$ rectal-shin ( $\left.{ }^{\circ} \mathrm{C}\right)$} \\
\hline Mean at $2 \mathrm{~h}$ & 1.38 & 2.14 & $-0.76(-1.41$ to -0.11$)$ \\
\hline Rate of change/h & 0.00 & 0.13 & $-0.13(-0.19$ to -0.07$)$ \\
\hline \multicolumn{4}{|l|}{ Ambient ( ${ }^{\circ} \mathrm{C}$ ) } \\
\hline Mean at $2 \mathrm{~h}$ & 16.01 & 17.45 & $-1.44(-2.65$ to -0.23$)$ \\
\hline Rate of change/h & -0.20 & -0.15 & $-0.06(-0.11$ to -0.01$)$ \\
\hline
\end{tabular}

difference in mean overnight rectal temperature between bed-share and cot-sleep groups where infants shared the parental bedroom in the sleep laboratory. Rectal temperature reflects the outcome of thermoregulatory control. A trend towards a higher rectal temperature found in healthy infants may indicate a potential difficulty for infants with impaired control.

In our study, bed-sharing infants exhibited higher shin temperatures than cot infants; these continued to increase overnight, thus maintaining a consistent rectal-shin temperature difference in the bed-share group. Decreasing shin temperatures in the cot group lead to an increase in rectalshin difference overnight. Shin temperature reflects the peripheral vasodilatory response to the thermal environment, an indicator of thermoregulatory activity of the infant to maintain a constant core temperature. Bed-share infants had more thermal insulation, largely because of greater use of duvets and perhaps a reduced ability to lose heat due to the proximity of their mother, ${ }^{35}$ thus requiring more vasodilatation to maintain core temperature. Ambient temperature appeared not to contribute to the higher shin temperature, as this was significantly higher for cot infants, despite matching for season.

Bed-sharing infants were less likely to sleep in the supine position, which is associated with lower overnight rectal temperature than the side or prone position ${ }^{36}$ and a lower peripheral (foot) temperature. ${ }^{37}$ In the supine position infants are also more likely to uncover arms and hands ${ }^{36}$ and this, along with exposure of the face, are key factors in an infant's ability to dissipate heat. ${ }^{38}$

Infant rectal temperature rises with waking, ${ }^{28} 32$ and the decrease on returning to sleep is less than at sleep onset. ${ }^{28}$ Wailoo et al have shown that rectal temperature remains raised for an hour if the infant feeds during this awake period.$^{39}$ Bed-share infants have a higher axillary temperature than cot-sleep infants in quiet sleep, associated only with the infants' frequency of transient arousals with movement. ${ }^{33}$ The increased shin temperature in the bed-share group may be in part due to increased waking and feeding. However, movements per hour in our study were the same in both groups.

Face covering occurred more often in the bed-share group. Carpenter and colleagues ${ }^{17}$ report the risk of SIDS associated with being found head covered as an odds ratio of 12.5 (95\% CI 6.47 to 24.1) and for evidence of sweating as 2.69 (1.75 to 4.14). As face covered infants become increasingly hot, evaporative heat loss ${ }^{40}$ and heat loss through bedding become more important. Mathematical modelling suggests that progressive hyperthermia rapidly becomes lethal in infants entrapped by bedclothes. ${ }^{38}$ Blair and colleagues ${ }^{41}$ found head covering to be the strongest predictor for SIDS in cot-sleeping infants (OR 18.5) but not bed-share infants. Identification of the position at death is less reliable during bed-sharing due to possible disruption by co-sleepers. The risk associated with head covering during sleep is not clear.

"First night effect" may influence behavioural and physiological recordings, ${ }^{42}$ although recent publications suggest not. ${ }^{43}$ We compared behavioural data on two consecutive nights from 10 infants, selected randomly, and found no significant difference on key behavioural indices such as sleep-time, number of infant movements/hour, feeds, and sleep position. To minimise "first night effect" we recorded physiological data and analysed behavioural data on the second night.

Although we measured rectal temperature from a small number of infants, some conclusions can be made. Infants were all healthy and despite warmer micro-environments, bed-share infants maintained normal rectal temperatures. Healthy infants, therefore, do not seem to be at increased risk of overheating when bed-sharing. Wailoo and colleagues ${ }^{27}$

Table 4 Thermal insulation and heat transfer characteristics of the bedding and clothing of infants

\begin{tabular}{|c|c|c|c|c|}
\hline Study group & $\begin{array}{l}\text { Bed-sharing } \\
\text { geometric mean (range) } \\
n=39\end{array}$ & $\begin{array}{l}\text { Cot-sleeping } \\
\text { geometric mean (range) } \\
n=39\end{array}$ & $\begin{array}{l}\text { Ratio of the mean* } \\
(95 \% \mathrm{Cl})\end{array}$ & $\mathbf{p}$ \\
\hline \multicolumn{5}{|l|}{ Bedding } \\
\hline Effective thickness (mm) & 58.89 (42.53-135.93) & $24.71(4.0-93.0) \ddagger$ & 2.35 (1.76 to 3.14$)$ & $<0.001$ \\
\hline "Dry" thermal insulationt $\left(\mathrm{m}^{2} \mathrm{~K} / \mathrm{W}\right)$ & $1.02(0.76-1.97)$ & $0.76(0.34-1.55) \ddagger$ & $1.33(1.13$ to 1.56$)$ & $<0.001$ \\
\hline \multicolumn{5}{|l|}{ Clothing } \\
\hline Effective thickness (mm) & $20.80(10.23-28.70)$ & $21.70(17.7-24.9)$ & 0.95 (0.89 to 1.02$)$ & 0.14 \\
\hline "Dry" thermal insulationt $\left(\mathrm{m}^{2} \mathrm{~K} / \mathrm{W}\right)$ & $0.54(0.26-0.71)$ & $0.56(0.45-0.63)$ & $0.95(0.89$ to 1.02$)$ & 0.15 \\
\hline
\end{tabular}


Table 5 Characteristics of the infants on the study night

\begin{tabular}{|c|c|c|c|c|}
\hline Study group & $\begin{array}{l}\text { Bed-sharing } \\
\text { geometric mean (range) } \\
n=38\end{array}$ & $\begin{array}{l}\text { Cot-sleeping } \\
\text { geometric mean (range) } \\
n=38\end{array}$ & Risk ratio $(95 \% \mathrm{Cl})^{*}$ & $\mathbf{p}$ \\
\hline $\begin{array}{l}\text { Face covered time (h/night) } \\
\text { No. awakenings/night } \\
\text { Total wake time (min/night) } \\
\text { No. feed sessions/night } \\
\text { No. movements/h }\end{array}$ & $\begin{array}{l}0.9(0-7.4) \\
4.6(1-10) \\
46.2(10.3-257.8) \\
3.7(0-6) \\
13.9(7.7-31.0)\end{array}$ & $\begin{aligned} & 0.2(0-4.9) \\
& 2.5(0-7) \\
& 26.6(0-215.0) \\
& 1.7(0-3) \\
& 14.6(7.2-27.5)\end{aligned}$ & $\begin{array}{l}5.62(3.08 \text { to } 10.25) \\
2.32(1.76 \text { to } 3.06) \\
1.41(0.78 \text { to } 2.56) \\
3.70(2.50 \text { to } 5.49) \\
0.93(0.80 \text { to } 1.08)\end{array}$ & $\begin{array}{c}<0.001 \\
<0.001 \\
0.25 \\
<0.001 \\
0.35\end{array}$ \\
\hline $\begin{array}{l}\text { No. in sleep position }>50 \% \text { night }(\mathrm{n}(\%)) \\
\text { Supine } \\
\text { Side } \\
\text { Prone }\end{array}$ & $\begin{array}{l}13(33) \\
25(63) \\
0(0)\end{array}$ & $\begin{array}{l}29(73) \\
7(18) \\
2(5)\end{array}$ & $\begin{array}{l}\text { Odds ratio }(95 \% \mathrm{Cl}) \\
1 \\
8.47(2.85 \text { to } 25.14) \\
-\end{array}$ & $<0.001$ \\
\hline
\end{tabular}

reported that cot-sleeping infants, overwrapped for environmental conditions, maintained normal core temperatures overnight. Infants with high risk factors for SIDS, such as maternal smoking during pregnancy, may have poorly developed thermoregulatory control, placing them at an increased risk of SIDS when exposed to warmer microenvironments present in bed-sharing. Tuffnell ${ }^{45}$ reported that bottle-fed infants of smoking mothers had higher overnight mean rectal temperatures. We had insufficient smokers' infants to investigate effects of smoking on thermoregulation. The low number of smokers among the bed-sharers, the high rate of breast feeding and maternal tertiary education, and the active choice to bed-share suggest our sample did not cover the full spectrum of bed-sharers where identified risks associated with bed-sharing are prevalent. Further to this, an association between bed-sharing and breast feeding that has been reported ${ }^{146}{ }^{47}$ has not been found among inner city, low income families in the USA. ${ }^{48}$

It appears that bed-sharing infants at low risk of SIDS were in a significantly warmer environment (bedding plus being close to an adult), were more likely to wake and feed, and more likely to become face covered-a potentially significant heat stress. Cot-sleeping infants, on the other hand, were in a heat conservation mode. In this study all infants maintained a normal core temperature. Future studies targeting infants at high risk of SIDS are needed to identify how risk factors might impact on infant and parental behaviour and on vulnerable infant physiology during bed-sharing.

\section{ACKNOWLEDGEMENTS}

This study was supported by a grant from the Health Research Council of New Zealand. The authors would like to thank: Charissa Makowharemahihi and Amanda Phillips for research assistance, Sheila Williams for statistical advice, Christine Rimene for advice on cultural aspects, Cheryl Wilson for data on thickness and thermal insulation of typical single layer New Zealand bedding and infant clothing, and the families that participated in the study.

\section{Authors' affiliations}

S A Baddock, B C Galland, M G S Beckers, B J Taylor, D P G Bolton, Department of Women's \& Children's Health, Dunedin School of Medicine, University of Otago, Dunedin, New Zealand

\section{REFERENCES}

1 Arnestad M, Andersen M, Vege A, et al. Changes in the epidemiological pattern of sudden infant death syndrome in southeast Norway, 1984-1998: implications for future prevention and research. Arch Dis Child 2001;85:108-15

2 Willinger M, Ko CW, Hoffman $\mathrm{HJ}$, et al. National infant sleep positions. Trends in infant bed sharing in the United States, 1993-2000: the National Infant Sleep Position study, Arch Pediatr Adolesc Med 2003;157:43-9.

3 Hooker E, Ball HL, Kelly PJ. Sleeping like a baby: attitudes and experiences of bedsharing in northeast England. Medical Anthropology 2001;19:203-22.

4 McKenna J, Mosko S, Richard C, et al. Experimental studies of infant-parent co-sleeping-mutual physiological and behavioral influences and their relevance to SIDS (sudden infant death syndrome). Early Hum Dev 1994;38:187-201.

5 Baddock SA, Day HF, Rimene CR, et al. Bedsharing practices of different cultural groups. In: SIDS 2000, 6th SIDS International Conference. Auckland, $\mathrm{NZ}, 2000$.

6 Ball HL, Hooker E, Kelly PJ. Where will the baby sleep? Attitudes and practices of new and experienced parents regarding cosleeping with their newborn infants. Am Anthropol 1999;101:143-51.

7 Abel S, Park J, Tipene-Leach D, et al. Infant care practices in New Zealand: a cross-cultural qualitative study. Soc Sci Med 2001;53:1135-48.

8 McKenna JJ, Mosko SS. Sleep and arousal, synchrony and independence, among mothers and infants sleeping apart and together (same bed): an experiment in evolutionary medicine. Acta Paediatr Suppl 1994;397:94-102.

9 McKenna JJ, Mosko SS, Richard CA. Bedsharing promotes breastfeeding. Pediatrics 1997:100:214-19.

10 Mosko S, Richard C, McKenna J, et al. Infant sleep architecture during bedsharing and possible implications for SIDS. Sleep 1996;19:677-84

11 Young J. Night-time behaviour and interactions between mothers and their infants of low risk for SIDS: a longitudinal study of room-sharing and bedsharing. PhD thesis. University of Bristol, 1999.

12 Scragg R, Mitchell EA, Taylor BJ, et al. Bed sharing, smoking, and alcohol in the sudden infant death syndrome. New Zealand Cot Death Study Group. BMJ 1993;307:1312-18.

13 Blair P, Fleming P, Smith I, et al. Babies sleeping with parents: case-control study of factors influencing the risk of the sudden infant death syndrome. BMJ 1999;319:1457-62.

14 Gessner BD, Ives GC, Perham-Hester KA. Association between sudden infant death syndrome and prone sleep position, bed sharing, and sleeping outside an infant crib in Alaska. Pediatrics 2001;108:923-7.

15 lyasu S, Randall L, Welty TK, et al. Risk factors for sudden infant death syndrome among northern plains Indians. JAMA 2002;288:2717-23.

16 James $C$, Klenka H, Manning D. Sudden infant death syndrome: bed sharing with mothers who smoke. Arch Dis Child 2003;88:112-13.

17 Carpenter RG, Irgens LM, Blair PS, et al. Sudden unexplained infant death in 20 regions in Europe: case control study. Lancet 2004;363:185-91.

18 Carroll-Pankhurst C, Mortimer EA. Sudden infant death syndrome, bedsharing, parental weight, and age at death. Pediatrics 2001;107:530-6.

19 Flick L, White DK, Vemulapalli C, et al. Sleep position and the use of soft bedding during bed sharing among African American infants at increased risk for sudden infant death syndrome. J Pediatr 2001;138:338-43.

20 Hauck FR, Herman SM, Donovan M, et al. Sleep environment and the risk of sudden infant death syndrome in an urban population: the Chicago Infant Mortality Study. Pediatrics 2003;111:1207-14.

21 Campbell AJ, Galland BC, Bolton DPG, et al. Ventilatory responses to rebreathing in infants exposed to maternal smoking. Acta Paediatr $2001 ; 90: 793-800$.

22 Lewis KW, Bosque EM. Deficient hypoxia awakening response in infants of smoking mothers: possible relationship to sudden infant death syndrome. J Pediatr 1995;127:691-9.

23 Filiano JJ, Kinney $\mathrm{HC}$. A perspective on neuropathologic findings in victims of the sudden infant death syndrome: the triple-risk model. Biol Neonate 1994:65: 194-7.

24 Nelson EA, Taylor BJ, Weatherall IL. Sleeping position and infant bedding may predispose to hyperthermia and the sudden infant death syndrome. Lancet 1989;1:199-201.

25 Fleming PJ, Gilbert R, Azaz Y, et al. Interaction between bedding and sleeping position in the sudden infant death syndrome: a population based case-control study. BMJ 1990;301:85-9.

26 Ponsonby AL, Dwyer T, Cochrane JA, et al. Characteristics of the infant thermal environment in the control population of a case-control study of SIDS. J Paediatr Child Health 1992;28:S36-40.

27 Wailoo MP, Petersen SA, Whittaker $\mathrm{H}$, et al. The thermal environment in which 3-4 month old infants sleep at home. Arch Dis Child 1989;64:600-4

28 Brown PJ, Dove RA, Tuffnell CS, et al. Oscillations of body temperature at night. Arch Dis Child 1992;67:1255-8.

29 Franco $\mathbf{P}$, Lipshutz W, Valente F, et al. Decreased arousals in infants who sleep with the face covered by bedclothes. Pediatrics 2002;109:1112-17.

30 Tuffnell CS, Petersen SA, Wailoo MP. Higher rectal temperatures in cosleeping infants. Arch Dis Child 1996;75:249-50. 
31 Ball HL. Triadic bed-sharing and infant temperature. Child Care Health Dev 2002;28:55-8.

32 Sawczenko A, Galland BC, Young J, et al. Night time mother- infant interactive behaviour and physiology: a longitudinal comparison of room sharing versus bedsharing ("co-sleeping"). Pediatr Pulmonol 1995;20:341.

33 Richard CA. Increased infant axillary temperatures in non-REM sleep during mother-infant bed-sharing. Early Hum Dev 1999;55:103-11.

34 Wilson CA, Niven BE, Laing RM. Estimating thermal resistance of the bedding assembly from thickness of materials. International Journal of Clothing Science and Technology 1999;11:262-76.

35 Karlsson H. Skin to skin care:heat balance. Arch Dis Child Fetal Neonatal Ed 1996;75:F130-2.

36 North RG, Petersen SA, Wailoo MP. Lower body temperature in sleeping supine infants. Arch Dis Child 1995:72:340-2.

37 Skadberg BT, Markestad T. Consequences of getting the head covered during sleep in infancy. Pediatrics 1997; 100:E61-7.

38 Bolton DP, Nelson EA, Taylor BJ, et al. Thermal balance in infants. J Appl Physiol 1996:80:2234-42.

39 Wailoo MP, Petersen SA, Whitaker H. Disturbed nights and 3-4 month old infants: the effects of feeding and thermal environment. Arch Dis Child 1990;65:499-501.
40 Rutter N, Hull D. Response of term babies to a warm environment. Arch Dis Child 1979;54:178-83

41 Blair P, Fleming D, Smith IJ, et al. Are risk factors for SIDS infants found sharing the parental bed different from those found in the cot? In: 7th SIDS International Conference. Florence, Italy, 2002:69-70.

42 Agnew HW, Webb WB, Williams RL. The first night effect: an EEG study of sleep. Psychophysiology 1966;2:263-6.

43 Katz ES, Greene MG, Carson KA, et al. Night-to-night variability of polysomnography in children with suspected obstructive sleep apnea. J Pediatr 2002; 140:589-94.

44 Kronholm E, Alanen E, Hyyppa MT. Sleep movements and poor sleep in patients with non-specific somatic complaints. I. No first-night effect in poor and good sleepers. J Psychosom Res 1987;31:623-9.

45 Tuffnell CS, Petersen SA, Wailoo MP. Factors affecting rectal temperature in infancy. Arch Dis Child 1995;73:443-6.

46 Ball HL. Breastfeeding, bed-sharing and infant sleep. Birth 2003;30:181-8.

47 Vogel A, Hutchison BL, Mitchell EA. Factors associated with the duration of breastfeeding. Acta Paediatr 1999:88:1320-6.

48 Brenner RA, Simons-Morton BG, Bhaskar B, et al. Infant-parent bed sharing in an inner-city population. Arch Pediatr Adolesc Med 2003; 157:33-9.

\section{Clinical Evidence - Call for contributors}

Clinical Evidence is a regularly updated evidence-based journal available worldwide both as a paper version and on the internet. Clinical Evidence needs to recruit a number of new contributors. Contributors are healthcare professionals or epidemiologists with experience in evidence-based medicine and the ability to write in a concise and structured way.

Areas for which we are currently seeking authors:

- Child health: nocturnal enuresis

- Eye disorders: bacterial conjunctivitis

- Male health: prostate cancer (metastatic)

- Women's health: pre-menstrual syndrome; pyelonephritis in non-pregnant women

However, we are always looking for others, so do not let this list discourage you.

Being a contributor involves:

- Selecting from a validated, screened search (performed by in-house Information Specialists) epidemiologically sound studies for inclusion.

- Documenting your decisions about which studies to include on an inclusion and exclusion form, which we keep on file.

- Writing the text to a highly structured template (about 1500-3000 words), using evidence from the final studies chosen, within 8-10 weeks of receiving the literature search.

- Working with Clinical Evidence editors to ensure that the final text meets epidemiological and style standards.

- Updating the text every six months using any new, sound evidence that becomes available. The Clinical Evidence in-house team will conduct the searches for contributors; your task is simply to filter out high quality studies and incorporate them in the existing text.

- To expand the topic to include a new question about once every 12-18 months.

If you would like to become a contributor for Clinical Evidence or require more information about what this involves please send your contact details and a copy of your CV, clearly stating the clinical area you are interested in, to Klara Brunnhuber (kbrunnhuber@ bmigroup.com).

\section{Call for peer reviewers}

Clinical Evidence also needs to recruit a number of new peer reviewers specifically with an interest in the clinical areas stated above, and also others related to general practice. Peer reviewers are healthcare professionals or epidemiologists with experience in evidence-based medicine. As a peer reviewer you would be asked for your views on the clinical relevance, validity, and accessibility of specific topics within the journal, and their usefulness to the intended audience (international generalists and healthcare professionals, possibly with limited statistical knowledge). Topics are usually 1500-3000 words in length and we would ask you to review between 2-5 topics per year. The peer review process takes place throughout the year, and our turnaround time for each review is ideally 10-14 days.

If you are interested in becoming a peer reviewer for Clinical Evidence, please complete the peer review questionnaire at www.clinicalevidence.com or contact Klara Brunnhuber (kbrunnhuber@bmjgroup.com). 